\title{
Deposition Geometrical Characteristics of Wire Arc Additive Manufactured AA2219 Aluminium Alloy With Cold Metal Transfer Pulse Advance Arc Mode
}

\section{Yazhou Zhang}

Huazhong University of Science and Technology

Ming Gao ( $\square$ mgao@mail.hust.edu.cn )

Huazhong University of Science and Technology

Yang Lu

Huazhong University of Science and Technology

Wenbo Du

Army Academy of Armored Forces

\section{Research Article}

Keywords: Aluminium alloy, Wire and arc additive manufacturing, Cold metal transfer pulse advance arc mode, Deposition geometrical characteristic, Dimension model

Posted Date: December 28th, 2021

DOI: https://doi.org/10.21203/rs.3.rs-1181416/v1

License: (c) (i) This work is licensed under a Creative Commons Attribution 4.0 International License. Read Full License 


\section{Abstract}

A cold metal transfer pulse advance (CMT-PA) arc mode was employed in this paper for the additive manufacturing of Al alloy. The effects of process parameters on the surface morphology and effective width percentage were investigated. And a deposition width model was built by the multiple linear regressions. Based on the principle that the volume of sample is equal to that of filler wire, a deposition height model was simultaneously derived. The results show that the process parameters affect the trends of droplet spreading in horizontal direction and molten pool tangential direction by changing the heat input and arc force. The disparity between two trends directly determines the final deposition geometrical characteristics. The influences of three factors on the effective width percentage show a trend of first increasing and then decreasing. So it provides a process window of good deposition forming. Using the optimal parameter in the window, the effective width percentage reaches to $83 \%$ and machining allowance is only $0.8 \mathrm{~mm}$, which significantly improves materials utilization and reduces manufacturing costs. Besides, the error rates of deposition width and height models are less than $4 \%$ and $6 \%$, respectively. Two models can facilitate manufacturing different size parts and make a profit for the actual production.

\section{Highlights}

1 The influential mechanisms of process parameters on the deposition geometrical characteristics are analyzed. Process parameters can affect the trends of droplet spreading in horizontal direction and molten pool tangential direction. The disparity between two trends determines the final deposition morphology.

2 This paper studies the influence of process parameters on the effective width percentage and provides a process window of good deposition forming, which can improve materials utilization and reduce manufacturing costs.

3 Effective deposition width and height models are established for the convenience of manufacturing different size parts in the actual production.

\section{Introduction}

Wire and arc additive manufacturing (WAAM) is an additive manufacturing technique that an electric arc was used as the heat source and metal wire as the feed material. It can directly fabricate large threedimensional (3D) parts and has fulfilled near net shape to a great extent, which just need a small amount of machining to meet the target dimension and accuracy requirements [1-5]. Recently, WAAM has attracted much attention for manufacturing large, meter-scale aluminium alloy parts both at home and abroad [6, 7]. This technique not only saves many raw materials compared with traditional machining process, but also greatly shortens the manufacturing cycle and reduces the cost. In particular, a variable polarity arc can provide effective oxide cleaning of the filler wire and previous deposition layer alternately 
which helps to reduce porosity defects and improve density. So, it can meet the increasingly stringent requirements on the property, accuracy, manufacturing cost and production cycle for large aerospace aluminium alloy parts [8-11].

WAAM technique itself indicates that the arc characteristic plays a key role in the forming process, so it is crucial to choose an excellent arc mode. Cold metal transfer (CMT) developed by Fronius provides a coupling between the filler wire feeding/retraction motion and metal droplet detachment through a special digital control system, which can complete the droplet transfer under an extremely low short circuit current smoothly. It can reduce the heat input and create a spatter-free material filling process [1215]. In order to realize the hybrid droplet transfer, Fronius further developed CMT Advance (CMT-A) and CMT Pulse Advance (CMT-PA) hybrid arc modes [16-18]. In recent years, many scholars have tried to conduct additive manufacturing of aluminium alloys based on CMT technology. Jiang et al. [19] studied the effects of cooling time and deposition strategy on the forming performance of 5356 aluminium alloy with CMT arc mode. The study showed suitable cooling time between the interlayers can improve the shaping accuracy, and reciprocating deposition strategy can reduce the defects of arc starting and ending. Cong et al. [20] investigated the effect of four CMT arc modes on the porosity characteristic of additive manufactured Al-6.3Cu alloy. They found that pure CMT process produced a large amount of gas pores, and CMT-PA proved to be the most suitable process for depositing aluminium alloy due to its excellent performance in controlling the heat input and cathode cleaning. Zhang et al. [21] conducted Al$6 \mathrm{Mg}$ alloy parts under CMT-PA arc mode. Uniform equiaxed grains in size of 20.6-28.5 $\mu \mathrm{m}$ were obtained, and the tensile strength with a maximum of $333 \mathrm{MPa}$ was higher than that of forging Al-6Mg alloys. This also verified the superiority of CMT-PA over other arc modes.

In addition, some scholars have explored the influence of hybrid technique on the forming performance, microstructure and property of WAAMed aluminium alloy. Zhang et al. [22] integrated WAAM and traditional milling technology to form AI5Si alloy. Compared with pure WAAM, this hybrid additive/subtractive manufacturing helped to reduce the side profile fluctuation and machining allowance to achieve precise control of the forming. Gu et al. [23, 24] employed inter-layer rolling process and post-deposition heat treatment into the WAAM deposition. The results indicated that the UTS and YS of the WAAMed Al-6.3Cu alloys exceeded $450 \mathrm{MPa}$ and $305 \mathrm{MPa}$ respectively after inter-layer rolling and T6 heat treatment. The high-density dislocations and fine sub-grains with relatively low misorientation in the rolled alloy are the main reasons for improving tensile properties. However, although the hybrid technique can improve the forming accuracy, it will significantly reduce forming efficiency and increase limitations during fabricating large parts with complex geometrical shapes.

As we all know, forming accuracy and geometrical characteristic of WAAMed parts directly determine the subsequent machining allowance, further affect material utilization and manufacturing costs. However, we can see that the current research mainly focused on the improvement of microstructure and inner defects. However, there was no comprehensive and systematic study in the process stability and geometrical characteristics of WAAM with CMT technology. In particular, few special studies are 
conducted on the forming characteristic of CMT-PA arc mode which can obtain better microstructure and property.

In view of this, this paper focus on the deposition geometrical characteristics of WAAMed AA2219 alloy with CMT-PA arc mode. First, the manufacturability and typical surface morphology of the arc mode were studied. Then, the effective width percentage was taken as an index to optimize the process parameters and improve forming stabilities. Finally, a multiple linear regression method was employed to construct the deposition width model. This study will provide the technical support and scientific principle for fabricating large-scale and complex Al alloys parts for aeronautic and astronautic applications.

\section{Experimental}

Experiments were carried out using the arc additive manufacturing setup consisting of a Fronius CMTAdvanced power source, and a M-710iC/50 industrial robot. A stagger deposition strategy was employed to manufacture thin-wall samples, as shown in Fig. 1. ER2319 alloy wire with diameter of $1.2 \mathrm{~mm}$ was used as the filler material after being dried at $100^{\circ} \mathrm{C}$ for two hours. $20 \mathrm{~mm}$-thickness 2A12-T6 Al plate was applied as the forming substrate on which the oxide film and greasy dirt were cleaned with a stainless steel brush and acetone respectively before using. The chemical compositions of the substrate and filler wire were presented in Table 1. A high speed camera system was employed to observe the arc shape and droplet transfer behavior in real time.

Table 1

Chemical constituents of welding wire and substrate (wt.\%)

\begin{tabular}{|lllllllll|}
\hline Elements & $\mathrm{Cu}$ & $\mathrm{Mn}$ & $\mathrm{Si}$ & $\mathrm{Mg}$ & $\mathrm{Fe}$ & $\mathrm{Zn}$ & $\mathrm{Ti}$ & $\mathrm{Al}$ \\
\hline ER2319 & $5.8-6.8$ & $0.2-0.4$ & 0.2 & 0.02 & 0.3 & 0.1 & $0.1-0.2$ & Bal. \\
2A12 & $3.8-4.9$ & $0.3-0.9$ & 0.5 & $1.2-1.8$ & $0-0.5$ & 0.3 & 0.15 & Bal. \\
\hline
\end{tabular}

In order to compare the manufacturability characteristics of different arc modes, CMT, CMT-A and CMTPA were employed in additive manufacturing AA2219 alloy thin-wall samples respectively. Their specific arc waveforms are shown in Fig. 2. CMT-A arc mode consists of an electrode positive CMT (EP-CMT) phase and an electrode negative CMT (EN-CMT) phase, while CMT-PA arc mode is made up of an electrode positive pulse (EP-Pulse) phase and an EN-CMT phase. The process parameters of three modes were shown in Table 2. The wire feeding speed was set at $6.5 \mathrm{~m} / \mathrm{min}$, and the current and voltage would match automatically according to different arc modes. The heat input $(H I)$ can be calculated by the formula (1).

$H I(\mathrm{~J} / \mathrm{mm})=\eta U I / V(1)$

Where $U$ is arc voltage, $/$ is arc current, $v$ is scanning speed, respectively, and $\eta$ is the arc thermal efficiency of CMT and normally is set to 0.8 [25]. 
Table 2

Processing parameters using different arc modes

\begin{tabular}{|c|c|c|c|c|c|c|}
\hline $\begin{array}{l}\text { Sample } \\
\text { number }\end{array}$ & $\begin{array}{l}\text { Arc } \\
\text { mode }\end{array}$ & $\begin{array}{l}\text { Wire feeding } \\
\text { speed } \\
v_{w} /\left(\mathrm{m} \mathrm{min}^{-1}\right)\end{array}$ & $\begin{array}{l}\text { Arc } \\
\text { current } \\
I /(A)\end{array}$ & $\begin{array}{l}\text { Arc } \\
\text { voltage } \\
U /(V)\end{array}$ & $\begin{array}{l}\text { Scanning } \\
\text { speed } \\
v /\left(\mathrm{mm} \mathrm{s}^{-1}\right)\end{array}$ & $\begin{array}{l}\text { Heat input } \\
H I /(\mathrm{J} \\
\left.\mathrm{mm}^{-1}\right)\end{array}$ \\
\hline 1 & CMT & 6.5 & 144 & 16.4 & 7 & 269.9 \\
\hline 2 & CMT-A & 6.5 & 131 & 14.6 & 7 & 218.6 \\
\hline 3 & CMT-PA & 6.5 & 100 & 11.7 & 7 & 133.7 \\
\hline
\end{tabular}

CMT-PA was selected as the research object among the three arc modes, because it can get better microstructure and property $[20,21]$. Ten groups of experiment were designed and shown in Table 3 , including three factors, i.e., arc current $(I)$, scanning speed $(v)$ and ratio of EP to EN $(r)$. The ratio of EP to EN represents the time ratio of EP-Pulse phase to EN-CMT phase overall the whole cycle of the CMT-PA arc mode. 70-layer thin-wall samples were produced to analysis the effects of process parameters on the deposition geometrical characteristics of WAAMed Al alloy. In order to eliminate heat accumulation, the next layer would not been conducted until the temperature of deposition surface is below $50{ }^{\circ} \mathrm{C}$.

Table 3

Processing parameters of CMT-PA mode experiments

\begin{tabular}{|c|c|c|c|c|c|}
\hline $\begin{array}{l}\text { Sample } \\
\text { number }\end{array}$ & $\begin{array}{l}\text { Arc } \\
\text { current } \\
I /(A)\end{array}$ & $\begin{array}{l}\text { Scanning } \\
\text { speed } \\
v /\left(\mathrm{mm} \mathrm{s}^{-1}\right)\end{array}$ & $\begin{array}{l}\text { Ratio of EP to EN } \\
r\end{array}$ & $\begin{array}{l}\text { Arc } \\
\text { voltage } \\
U /(V)\end{array}$ & $\begin{array}{l}\text { Heat input } \\
H I /(\mathrm{J} \\
\left.\mathrm{mm}^{-1}\right)\end{array}$ \\
\hline$\# 1$ & 85 & 7 & 0.9 & 11.3 & 109.8 \\
\hline \#2 & 95 & 7 & 0.9 & 11.5 & 124.9 \\
\hline \#3 & 105 & 7 & 0.9 & 11.7 & 140.4 \\
\hline \#4 & 115 & 7 & 0.9 & 11.9 & 156.4 \\
\hline \#5 & 95 & 3 & 0.9 & 11.5 & 291.3 \\
\hline \#6 & 95 & 5 & 0.9 & 11.5 & 174.8 \\
\hline \#7 & 95 & 9 & 0.9 & 11.5 & 97.1 \\
\hline \#8 & 95 & 7 & 0.8 & 11.5 & 124.9 \\
\hline \#9 & 95 & 7 & 1.0 & 11.5 & 124.9 \\
\hline$\# 10$ & 95 & 7 & 1.1 & 11.5 & 124.9 \\
\hline
\end{tabular}

After the thin-wall sample is completed, three areas were selected along the deposition direction to measure their heights respectively, as shown in Fig. 1. The average of three values was taken as the final height of thin-wall sample. Then, the cross-sections of three areas were chosen to measure their effective 
width $W_{e}$ and total width $W$. The effective width percentage of every cross-section was calculated using the formula $\xi=W_{e} / W \times 100 \%$. The mean of three results was taken as the final effective width percentage of thin-wall sample. The laser displacement sensor was adopted to measure the side profile fluctuation of thin-wall samples.

\section{Results}

\subsection{Deposition process characteristics of different arc modes}

The samples deposited by CMT, CMT-A and CMT-PA arc modes are shown in Fig. 3 , from which it can be found that all these samples show bright metallic luster and has no any oxidative blackening on the surface. However, larger weld overlap defects are observed on the side surface of the CMT sample. And for the CMT-A sample, a serious necking phenomenon appears near the arc starting region. This defect becomes more and more serious with the increase of deposited layers, which finally leads to poor flatness on the upper surface. Besides, a slight crater occurs on the side surface. While as for the CMT-PA sample, we can see uniform and fish scale shaped weld bead.

Looking at the cross section morphology in Fig. 3 , it can be seen that the cross sections of three samples have the similar subarea characteristics, which all contain three regions, i.e., the broadening bottom area, middle area with stable size and arched top area. Therefore, a broadening forming section is required before obtaining the stable section. As for three arc modes, the broadening bottom section of CMT-PA is the maximal and reaches $6.0 \mathrm{~mm}$ in height. A gradual increase in the deposition width can reduce the stress concentration and avoid cracking between the thin-wall and substrate. Besides, the sample with this arc mode grows in vertical direction. While the samples under CMT and CMT-A modes tilt at the angle of 12 degrees and 5 degrees respectively, which easily lead to serious collapse of subsequent depositions. Comparing the three arc modes, it can be found that CMT-PA mode is able to obtain more stable forming and beautiful morphology than the other two. Good manufacturability characteristic demonstrates it will be very suitable for fabricating large-size Al alloy parts.

\subsection{Deposition geometrical characteristics with CMT-PA arc mode}

\subsubsection{Deposition morphology}

According to the process parameters in Table $3, \# 1$ - \#10 thin-wall samples were deposited under CMT-PA arc mode. Three typical samples are shown in Fig. 4. We can see under the larger scanning speed of 9 $\mathrm{mm} / \mathrm{s}$, such as \#7, it is easy to produce poor fusion and even discontinuous formation defects. What is more, these defects are not filled and improved in the subsequent additive manufacturing process, and finally lead to the surface craters on the thin-wall (see Fig. 4a). Whereas, using a lower scanning speed of $3 \mathrm{~mm} / \mathrm{s}$ or $5 \mathrm{~mm} / \mathrm{s}$, for example \#6, the deposition bulges outward and the transition area collapses 
inward (see Fig. 4b). In this case, a zigzag side surface appears and the deposition quality is seriously deteriorated. When the current and scanning speed match properly, such as \#2, we can get a uniform thinwall with a well flat side surface (see Fig. 4c).

\subsubsection{Effective width percentage}

The effective width percentage of cross-sections can be regarded as the material utilization rate to some extent. This is because the larger the ratio is, the smaller the machining allowance is, and the higher the material utilization rate is. Accordingly, this paper takes the ratio as the index to optimize process parameters, and studies the influence of process factors on the index results. The effective width percentages of 10 thin-wall samples are shown in Fig. 5. As can be seen, the range is from $56.1-79.7 \%$.

Figure 6 shows the influence of various process factors on the effective width percentage of thin-walls. Note that the effective width percentage first increases then decreases with the increase of arc current, and achieves the maximum value when the arc current reaches $95 \mathrm{~A}$. When the scanning speed varies from $3 \mathrm{~mm} / \mathrm{s}$ to $7 \mathrm{~mm} / \mathrm{s}$, the effective width percentage will increase from $56.1-79.7 \%$, which indicates deposition forming is obviously improved. However, the effective width percentage will begin to decrease if the scanning speed continues to increase. The thin walls have better effective width percentage when the ratio of EP to EN is at the range from 0.9 to 1.0. Besides, the range value $\mathrm{R}$ of each factor in Fig. 6 represents its influence degree on index results. By comparing the range value, it can be seen that the scanning speed has the greatest impact on the effective width percentage, followed by the arc current and ratio of EP to EN.

The analysis above shows that the influences of three factors on the effective width percentage all increase first and then decrease. This suggests that the process window can be obtained for good deposition forming, namely arc current of $92 \sim 101 \mathrm{~A}$, scanning speed of $6.3 \sim 7.5 \mathrm{~mm} / \mathrm{s}$, and ratio of EP to $\mathrm{EN}$ of $0.86 \sim 1.01$. Using process parameters in the window, the effective width percentage reaches the range from 75-79.7\% (\#2, \#3). As shown in Fig. 7 is the side surface fluctuation characteristics of three thin-wall samples. It is clear that the fluctuation degree of \#2 is much smaller than \#6 and \#7. In the meantime, its machining allowance is also the smallest and only $1.0 \mathrm{~mm}$, which is $52.4 \%$ and $28.6 \%$ lower than that of \#6 and \#7, respectively. As a result, this will greatly save filler materials and shorten the manufacturing cycle.

To verify the effectiveness of the process window, three thin-wall components were fabricated. Figure 8 shows the morphology with arc current of $95 \mathrm{~A}$, scanning speed of $7 \mathrm{~mm} / \mathrm{s}$ and ratio of EP to EN of 0.9 . It can be found that the side surface appears smooth and flat due to the obvious elimination of zigzag concave and convex defects. And its effective width percentage and machining allowance reach as high as $83 \%$ and only $0.8 \mathrm{~mm}$, respectively. This demonstrates that the process window is effective and reliable, which can greatly improve the deposition morphology, increase the materials utilization and reduce the manufacturing costs.

\subsubsection{Deposition dimension and model}


There is a strong requirement for enterprises to be able to manufacture different size parts. As described in sections 3.2.1 and 3.2.2, it can be seen that process parameters have noteworthy effects on the deposition geometrical characteristics. Therefore, establishing models to predict the deposition dimension is of great significance for the actual production of WAAMed Al alloy.

The deposition width $W$ and height $H$ of \#1-\#10 thin-wall samples are displayed in Table 4 . It shows that the deposition width and height vary greatly depending on different process parameters. The differences of deposition width and height between the \#1 and \#5 reach $3.9 \mathrm{~mm}$ and $42.3 \mathrm{~mm}$, respectively.

Table 4

Deposition width and height of \#1-\#10 thin-walls

\begin{tabular}{|lllllllllll|}
\hline $\begin{array}{l}\text { Sample } \\
\text { number }\end{array}$ & \#1 & \#2 & \#3 & \#4 & \#5 & \#6 & \#7 & \#8 & \#9 & \#10 \\
\hline$W(\mathrm{~mm})$ & 6.6 & 7.3 & 8.2 & 9.1 & 10.5 & 9.3 & 6.5 & 6.8 & 7.5 & 8.1 \\
\hline$H(\mathrm{~mm})$ & 142.2 & 155.8 & 163.7 & 172.3 & 184.5 & 157.9 & 148.3 & 158.9 & 156.4 & 143.8 \\
\hline
\end{tabular}

According to the above deposition width, the regression coefficient of each process factor was calculated by the multiple linear regression method, and the multiple regression equation of the deposition width was obtained as follows:

$W=1.824+0.082 I-0.744 v+3.381 r(2)$

Then, the goodness of fit of the regression equation was tested. The correlation coefficient $R^{2}$ is 0.954 . And the significance level $p(I), p(v), p(r)$ of F-test are $0.001,0.001,0.038$, respectively, all less than 0.05 . The results are able to demonstrate convincingly that three process factors have significant influence effect on the deposition width and the regression model is valid.

However, there is no significant correlation between the deposition height and the process parameters, so the linear regression method is not suitable for the prediction analysis of deposition height. Given this situation, the calculation model of deposition height was deduced according to the principle that the volume of sample was equal to that of filler wire in WAAM process. Since the middle region of the sample is stable in process and shape, we can assume that the deposition shape is a cuboid. And the deposition volume of each layer $V_{\text {deposition }}$ is as below:

$V_{\text {deposition }}=W h v t(3)$

In the formula, $W$ is the deposition width, $h$ is the deposition height of each layer, $v$ is the scanning speed and $t$ is the depositing time of each layer.

When the wire feeding speed is $v_{w}$ and the wire diameter is $D$, the molten wire volume of each layer $V_{\text {wire }}$ is as follows: 
$V_{\text {wire }}=\pi(D / 2)^{2} v_{w} t(4)$

On the basis of that the deposition volume $V_{\text {deposition }}$ and the molten wire volume $V_{\text {wire }}$ are equal, the deposition height of n-layers sample can be derived as follows:

$H=n h=\frac{\mathrm{n} \Pi \mathrm{D}^{2} \mathrm{v}_{\mathrm{w}}}{4 \mathrm{vW}}(5)$

For the sake of verifying the accuracy of deposition width and height models, new process parameters were designed and substituted into the regression equations (2) and (5) to obtain the corresponding predicted values of deposition width and height. Then, samples (T10T5) were produced to measure the actual size. The error rates between the actual values and the predicted values were calculated and illustrated in Fig. 9. The results indicate that the error rates $E_{\text {width }}$ of deposition width are all within $4 \%$, and the error rates $E_{\text {height }}$ of deposition height are less than $6 \%$. It is further proved that the two models are reliable and can be applied to predict the deposition size of WAAMed Al alloy parts.

\section{Discussions}

The spreading behavior of droplets and solidification of molten pool play a vital role to the forming stability and quality in the WAAM process. The force analysis of droplets in CMT-PA arc mode is shown in Fig. 10, including gravity $(G)$, surface tension $(\sigma)$, arc force $\left(F_{a}\right)$ and the buoyancy of pool liquid metals $\left(F_{b}\right)$. Among them, surface tension exists on the surface of the droplet, and has a negative correlation with the temperature of molten droplet. It will promote the transfer and spread of droplets when the contact angle is less than $\pi / 2$, which can be calculated by the formula as follows $[26,27]$ :

$\sigma=2 \pi k R\left(T_{0^{-}} T-\tau\right) / A_{m}(6)$

Where, $k$ is a constant related to materials; $R$ is the surface radius; $T_{0}$ is the critical temperature when surface tension is zero; $T$ is the liquid temperature; $\tau$ is a temperature constant; $A_{m}$ is the surface area of one mole atoms.

In general, the arc force $\left(F_{a}\right)$ includes electromagnetic force $\left(F_{c}\right)$, plasma stream force $\left(F_{f}\right)$ \spot pressure $\left(P_{s}\right)$ and short-circuit explosive force $\left(F_{e}\right)$ in the arc welding. For the droplets of completing transfer, however, electromagnetic force in the axial direction $\left(F_{c z}\right)$ and plasma stream force $\left(F_{f}\right)$ are the most important factors that affect metal spread and are calculated by the formula as follows [28-31]:

$F_{a}=F_{c z}+F_{f}=K I^{2} \ln \frac{r_{1}}{r_{0}}+\frac{\Pi}{2}\left(r_{1}^{2}-r_{0}^{2}\right) C_{d} \rho_{f} v_{f}^{2}(7)$

Where, $K$ is a constant; $I$ is arc current; $r_{0}$ is the upper surface radius of arc column; $r_{1}$ is the lower surface radius of arc column; $C_{d}$ is arc damping coefficient; $\rho_{f}$ is plasma density; $v_{f}$ is plasma density flowing velocity having a positive correlation with arc current. 
Under the combined action of above forces, the liquid metal inside the droplet flows downward along the curved inner wall. It will generate two kinds of droplet spreading trends. First, the droplet spreads in horizontal direction and becomes flat. Second, the droplet flows along the tangential direction at the junction of molten pool, droplet and air. The disparity between the two trends directly determines the surface morphology and effective width percentage after the solidification of liquid metal.

According to the formula (1), scanning speed can directly affect the heat input and then obviously change the temperature of droplet and molten pool in the WAAM process. When scanning speed is 9 $\mathrm{mm} / \mathrm{s}$, such as \#7 with a heat input of only $97.1 \mathrm{~J} / \mathrm{mm}$, the temperature of the liquid droplet is lower. And the strong surface tension helps the droplet metal flow along the tangential direction of molten pool (see Fig. 10a). However, the shortening of solidification time will be likely to lead to poor spreading or even discontinuous formation of liquid metal on the deposition surface. The uneven depositions easily result in the fluctuations of arc length and voltage, which can destroy the forming stability of the next layer. As a result, many crater defects are introduced into the surface of thin-walls. As the decrease of scanning speed, such as \#2 with a scanning speed of $7 \mathrm{~mm} / \mathrm{s}$ and heat input of $124.9 \mathrm{~J} / \mathrm{mm}$, the temperature of molten droplet rises and surface tension reduces. This helps to improve liquid metal flowabilities and increase the trend of droplet spreading in horizontal direction. Simultaneously, it is also accessible that small surface tension weakens the trend of droplet flowing along the tangential direction of molten pool. Surface craters will be eliminated and deposition appearance will be dramatically improved when two trends reach a dynamic equilibrium state to some extent (see Fig. 10b). In this case, the effective width percentage can be effectively increased to as high as $79.7 \%$ (\#2), which reduces the machining allowance greatly. But if scanning speed decreases continuously to below $5 \mathrm{~mm} / \mathrm{s}$, i.e., once the heat input exceeds $150 \mathrm{~J} / \mathrm{mm}$ (such as \#5, \#6), both the droplet and molten pool will be overheating. Under poor surface tension, the liquid metal inside the droplet flows close to the curved inner wall as shown in Fig. 10c. The trend of droplet spreading in horizontal direction and becoming flat is much stronger than that flowing along the tangential direction of molten pool. This will easily cause the deposition to bulge outwards and transition area to dent inward. Finally, the effective width percentage declines obviously, for instance, the effective width percentage of \#5 thin-wall has dropped to $56.1 \%$.

It is known that arc current has important influence on the heat input and arc force by the formula (1) and (7). Besides, the ratio of EP to EN will also affect the heat input and arc force in the CMT-PA process to some extent [10]. Figure 11 shows the arc shapes and droplet transfer process in the EP-Pulse and ENCMT phases. As you can see in the figures, EP-Pulse phase produces a strong bell shape arc with the maximum diameter of $6.2 \mathrm{~mm}$, which could produce a deep weld penetration. However, the arc in the ENCMT phase is elongated and only $2.2 \mathrm{~mm}$ in the maximum diameter which is about one third of EP-Pulse arc. At the same time, the arc energy is transferred from the workpiece to welding wire and mainly used to melt filler materials. As a consequence, the heat input in the EP-Pulse phase will be much larger than that in the EN-CMT phase. According to prior studies [32], the heat input in the EP-Pulse and EN-CMT phases are $467.8 \mathrm{~J} / \mathrm{mm}$ and $164.3 \mathrm{~J} / \mathrm{mm}$ respectively under the wire feeding speed of $5.0 \mathrm{~m} / \mathrm{min}$ and scanning speed of $5 \mathrm{~mm} / \mathrm{s}$. By observing the droplet transfer in Fig. 11, it can be found that the droplet in the EPPulse phase appears approximately elliptical shape, and an arc crater occurs on the molten pool surface. 
This indicates that the arc force in the EP-Pulse phase points to the molten pool and is much greater than that in the EN-CMT phase. Therefore, with the increase of ratio of EP to EN, the duration of the EP-Pulse phase will approach or even exceed that of the EN-CMT phase, and both the heat input and arc force in a whole cycle will gradually increase simultaneously.

It can be summarised from the above analysis that both the arc current and ratio of EP to EN will affect forming stabilities and deposition geometrical characteristics by the heat input and arc force. When the current is more than $105 \mathrm{~A}$ or ratio of EP to EN exceeds 1.0, such as \#4 and \#10, strong arc force going with poor surface tension will easily cause liquid metal to spread in horizontal direction, even flow out of control. In the meantime, strong droplet impact force in EP-Pulse phase will also lead to drastic oscillation and serious instability in molten pool. It will make it difficult to accurately control the shape of metals after solidification, thereby seriously lower the forming quality of deposition side surface.

In summary, two arcs with opposite polarities and a great disparity in temperature are constantly alternated in the CMT-PA mode. So, it not only can make the heat input level be controlled accurately, but also provide a wide adjustable range of heat input and excellent gap bridging capacity. This can guarantee that CMT-PA mode is superior to other modes on controlling deposition forming quality. However, proper process parameters are still necessary to obtain well-formed Al alloy parts even under the excellent arc mode.

\section{Conclusions}

AA2219 Al alloy thin-wall components were fabricated by arc wire additive manufacturing using a CMTPA arc mode. Based on the effective width percentage index, the process parameters were optimized. And the influential mechanisms of process parameters on the deposition morphology characteristics were analyzed. Besides, dimensional models of deposition width and height were finally established. The following conclusions can be drawn:

(1) The effects of three factors on the effective width percentage show a trend of first increasing and then decreasing. This provides a process window of good deposition forming, namely arc current of $92 \sim 101$ A, scanning speed of $6.3 \sim 7.5 \mathrm{~mm} / \mathrm{s}$, and ratio of EP to EN of $0.86 \sim 1.01$. Using the optimal parameter in the window, the effective width percentage reaches to $83 \%$ and machining allowance is only $0.8 \mathrm{~mm}$, which can significantly improve materials utilization and reduce manufacturing costs.

(2) The process parameters affect the spreading behaviors of liquid droplet and solidification process of molten pool by changing the heat input and arc force. With insufficient heat input, poor fusion and discontinuous formation will easily cause uneven deposition. Under the arc current above $101 \mathrm{~A}$, ratio of EP to EN in excess of 1.01 or scanning speed less than $6.3 \mathrm{~mm} / \mathrm{s}$, strong arc force going with poor surface tension will result in much larger trend of droplet spreading in horizontal direction than that along tangential direction of molten pool. This can lead to liquid metals flowing out of control and seriously lower the forming quality. Only using the process parameters in the window, can two trends reach a dynamic equilibrium state and excellent deposition appearance be obtained. 
(3) The error rates of deposition width and height models are less than $4 \%$ and $6 \%$, respectively. This proves that two models are effective for predicting forming dimensions and convenient to manufacture different size Al alloy parts.

\section{Declarations}

\section{Acknowledgments}

This research is financially supported by the National Natural Science Foundation of China (grant nos. 51775206) and the foundation of National Key Laboratory for Remanufacturing (No. 6142005200401).

Funding

This research is financially supported by the National Natural Science Foundation of China (grant nos. 51775206) and the foundation of National Key Laboratory for Remanufacturing (No. 6142005200401).

Competing Interests

The authors declare that they have no known competing financial interests or personal relationships that could have appeared to influence the work reported in this paper.

Author Contributions

Yazhou Zhang designed and conducted the experiments, organized the all data, and wrote the manuscript. Ming Gao evaluated the obtained data and supervised all research. Yang Lu and Wenbo Du completed the auxiliary data analysis work. All authors read and approved the final manuscript.

Corresponding author

Correspondence to Ming Gao.

\section{References}

1. Wang FD, Williams SW, Colegrove P, Antonysamy A (2013) Microstructure and mechanical properties of wire and arc additive manufactured Ti-6Al-4V. Metall Mater Trans A 44(2):968-977

2. Aiyiti W, Zhao W, Lu B (2006) Investigation of the overlapping parameters of MPAW-based rapid prototyping. Rapid Prototyp J 12(3):165-172

3. Liu LM, Zhuang ZL, Liu F, Zhu ML (2013) Additive manufacturing of steel-bronze bimetal by shaped metal deposition: interface characteristics and tensile properties. Int J Adv Manuf Technol 69:21312137

4. Xiong J, Zhang GJ (2014) Adaptive control of deposited height in GMA-based layer additive manufacturing. J Mater Process Technol 214:962-968 
5. Xiong J, Zhang GJ, Hu JW, Li YZ (2013) Forecasting process parameters for GMA-based rapid manufacturing using a closed-loop iteration based on neural network. Int J Adv Manuf Technol 69(1-4):743-751

6. DebRoy T, Wei HL, Zuback JS, Mukherjee T, Elmer JW, Milewski JO, Beese AM, Wilson-Heid A, De A, Zhang W (2018) Additive manufacturing of metallic components-process, structure and properties. Prog Mater Sci 92:112-224

7. Ding D, Pan Z, Cuiuri D, Li H (2015) Wire-feed additive manufacturing of metal components: Technologies, developments and future interests. Int J Adv Manuf Technol 81:465-481

8. Wang HJ, Jiang WH, Ouyang JH, Kovacevic R (2004) Rapid Prototyping of 4043 Al-alloy Parts by VPGTAW. J Mater Process Technol 148(1):93-102

9. Williams JC, Starke EA Jr (2003) Progress in structural materials for aerospace systems. Acta Mater 51(19):5775-5799

10. Wang FD, Williams S, Rush M (2011) Morphology investigation on direct current pulsed gas tungsten arc welded additive layer manufactured Ti6Al4V alloy. Int J Adv Manuf Technol 57:597-603

11. Ouyang JH, Wang H, Kovacevic R (2002) Rapid prototyping of 5356-aluminum alloy based on variable polarity gas tungsten arc welding process control and microstructure. Mater Manuf Processes 17(1):103-124

12. Pickin CG, Young K (2006) Evaluation of cold metal transfer (CMT) process for welding aluminium alloy. Sci Tech Weld Join 11(5):583-585

13. Wang J, Feng J, Wang Y (2008) Microstructure of Al-Mg dissimilar weld made by cold metal transfer MIG welding. Mater Sci Tech 24(7):827-831

14. Zhang H, Feng J, He P (2007) Interfacial phenomena of cold metal transfer (CMT) welding of zinc coated steel and wrought aluminium. Mater Sci Tech 24(11):1346-1349

15. Pickin C, Williams SW, Lunt M (2011) Characterisation of the cold metal transfer (CMT) process and its applications for low dilution cladding. J Mater Process Technol 211(3):496-502

16. Clark D, Bache MR, Whittaker MT (2008) Shaped metal deposition of a nickel alloy for aero engine applications. J Mater Process Technol 203(1-3):439-448

17. Williams SW, Martina F, Addison AC, Ding J, Pardal G, Colegrove P (2016) Wire + Arc Additive Manufacturing. Mater Sci Technol 32:641-647

18. Pan ZX, Ding DH, Wu BT, Cuiuri D, Li HJ, Norrish J (2018) Arc Welding Processes for Additive Manufacturing: A Review. Transactions on Intelligent Welding Manufacturing 3:3-24

19. Jiang YL (2013) Reseach on the rapid prototyping technology and forming process of aluminum alloy based on the CMT. Dissertation, Harbin Institute of Technology, Harbin

20. Cong BQ, Ding JL, Williams S (2015) Effect of arc mode in cold metal transfer process on porosity of additively manufactured Al-6.3\%Cu alloy. Int J Adv Manuf Technol 76(9-12):1593-1606

21. Zhang C, Li YF, Gao M (2018) Wire arc additive manufacturing of Al-6Mg alloy using variable polarity cold metal transfer arc as power source. Mater Sci Eng A 711:415-423 
22. Zhang S, Zhang YZ, Gao M, Wang FD, Li Q, Zeng XY (2019) Effects of milling thickness on wire deposition accuracy of hybrid additive/subtractive manufacturing. Sci Tech Weld Join 24(5):375381

23. Gu JL, Ding JL, Williams SW, Gu HM, Bai J, Zhai YC, Ma PH (2016) The strengthening effect of interlayer cold working and post-deposition heat treatment on the additively manufactured $\mathrm{Al}-6.3 \mathrm{Cu}$ alloy. Mater Sci Eng A 651:18-26

24. Gu JL, Ding JL, Williams SW, Gu HM, Ma PH, Zhai YC (2015) The effect of inter-layer cold working and post-deposition heat treatment on porosity in additively manufactured aluminum alloys. $\mathrm{J}$ Mater Process Technol 230:26-34

25. Azar AS (2015) A heat source model for cold metal transfer (CMT) welding. J Therm Anal Calorim 122(2):741-746

26. Wang XD, Peng XF, Min JC, Liu T (2001) Hysteresis of contact angle at liquid solid interface. Chinese J Basic Sci Eng 9(4):333-343

27. Yang LJ, Li H, Li JY, Zheng ZT (2004) Mechanics analysis of short circuit liquid bridge for $\mathrm{CO}_{2}$ welding. Electric Welding Machine 34(3):4-7

28. Huang HC (2018) Study on droplet transfer of CMT + P welding process in SAF2507 super duplex stainless Steel. Dissertation, Tianjin University, Tianjin

29. Chang YL, Liu XL, Lu L, Babkin AS, Lee BY, Gao F (2014) Impacts of external longitudinal magnetic field on arc plasma and droplet during short-circuit GMAW. Int J Adv Manuf Technol 70(9 12): $1543 \sim 1553$

30. Liu XL (2014) Mechanical analysis on arc plasma and droplet during short-circuit $\mathrm{CO}_{2}$ welding controlled by external magnetic fileds. Dissertation, Shenyang University of Technology, Shenyang

31. Li KH, Wu CS (2009) Mechanism of metal transfer in DE-GMAW. J Mater Sci Technol (Shenyang, China) 25(3):415418

32. Li JJ (2018) Study on metal transfer behavior and welding formation of 6061 aluminum alloy variable polarity CMT and CMT+P. Dissertation, Tianjin University, Tianjin

\section{Figures}

\section{Figure 1}

Schematic diagram of the WAAM process 

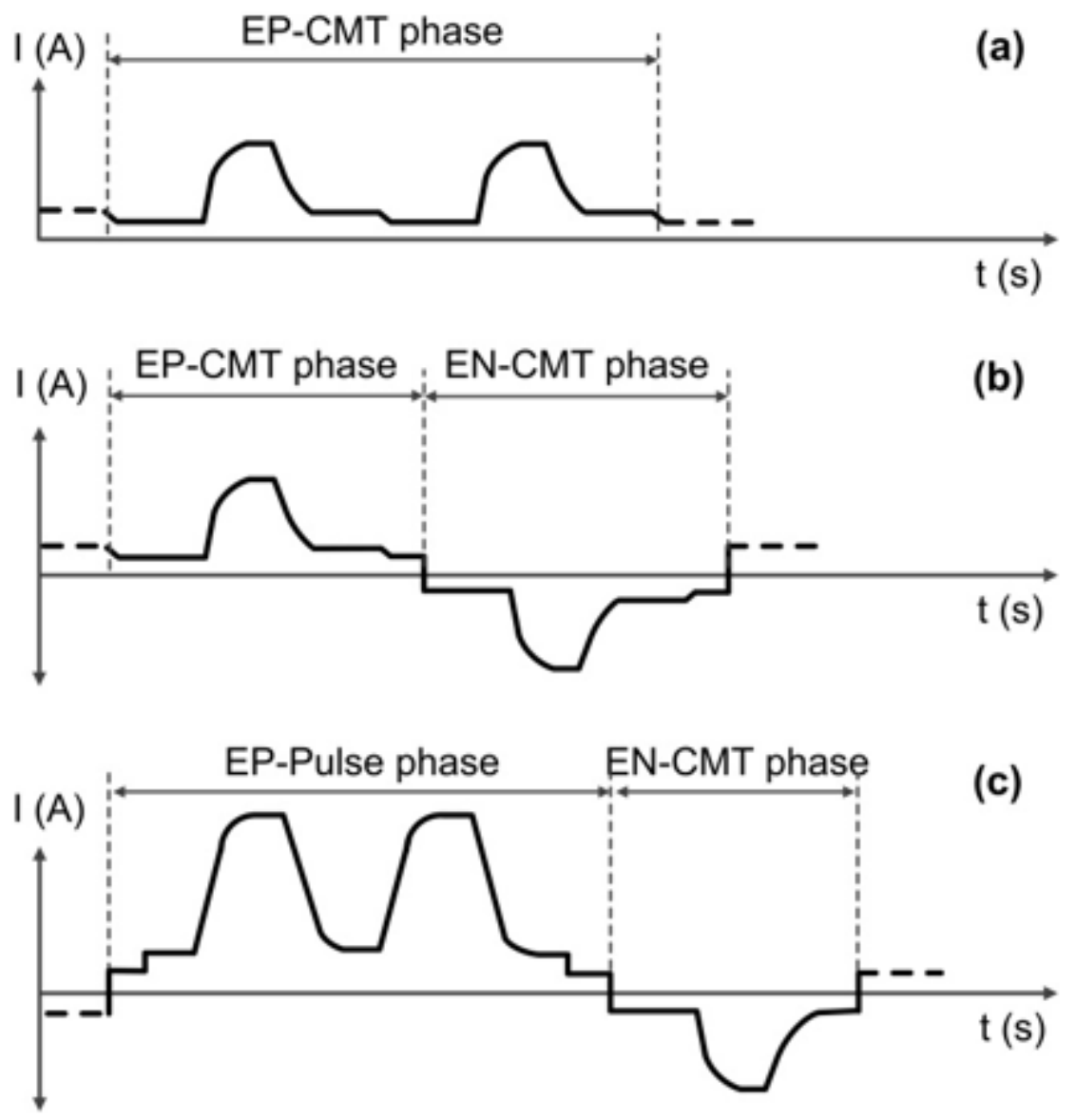

Figure 2

Arc current waveforms of (a) CMT, (b) CMT-A and (c) CMT-PA arc modes 

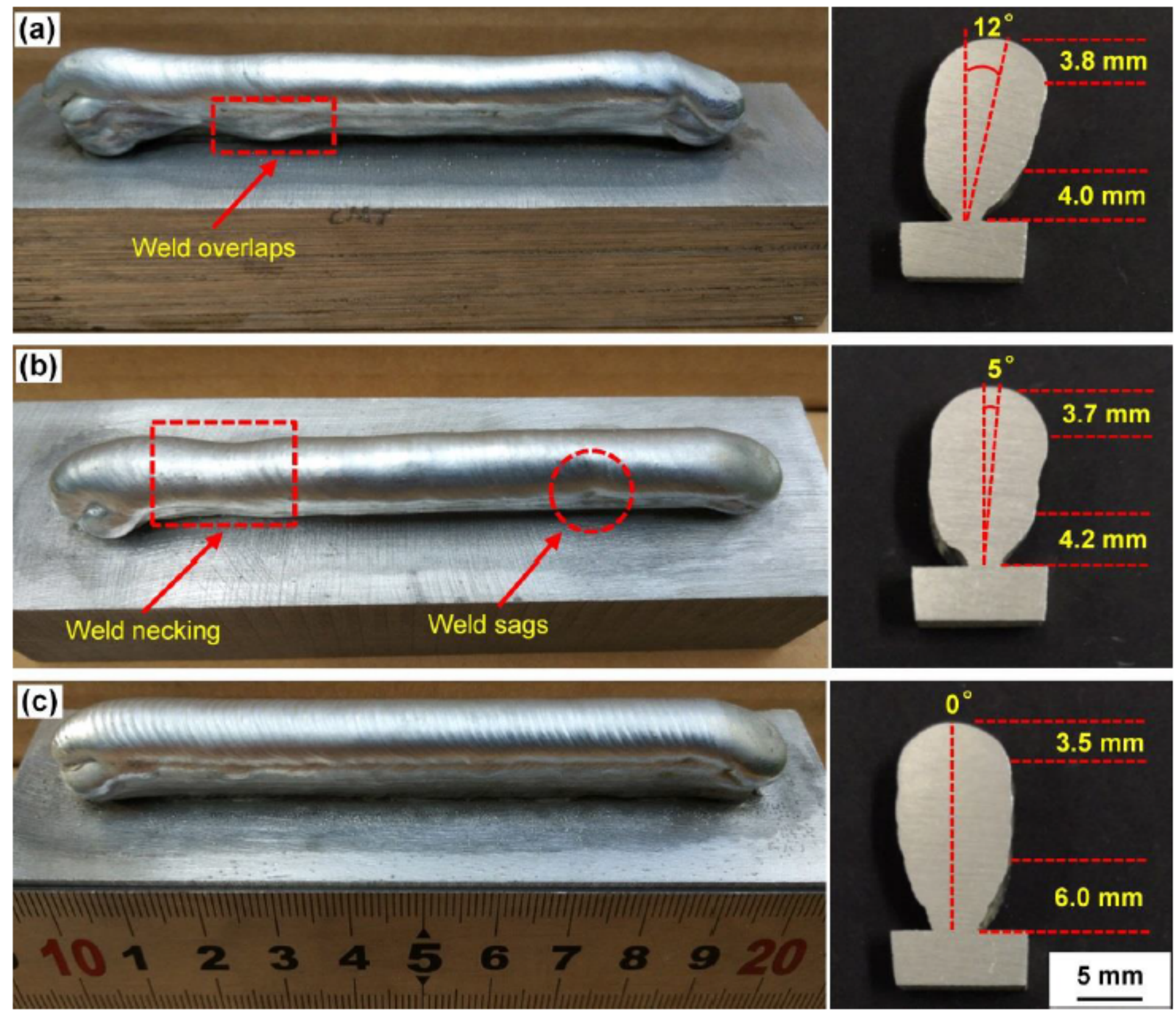

\section{Figure 3}

Surface morphologies and cross section appearances under (a) CMT, (b) CMT-A and (c) CMT-PA arc modes 

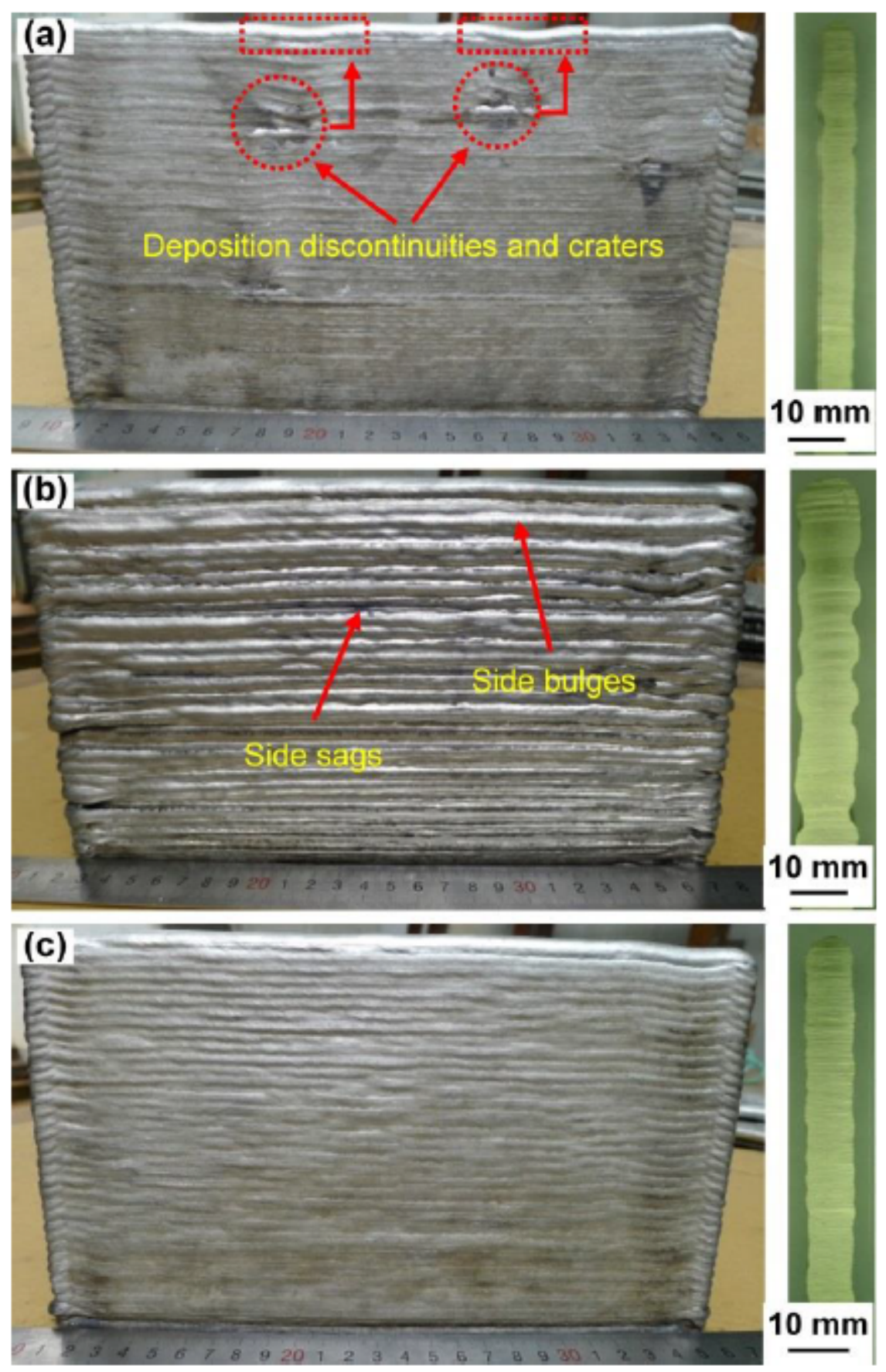

Figure 4

Typical appearances of (a) \#7, (b) \#6 and (c) \#2 thin-walls 


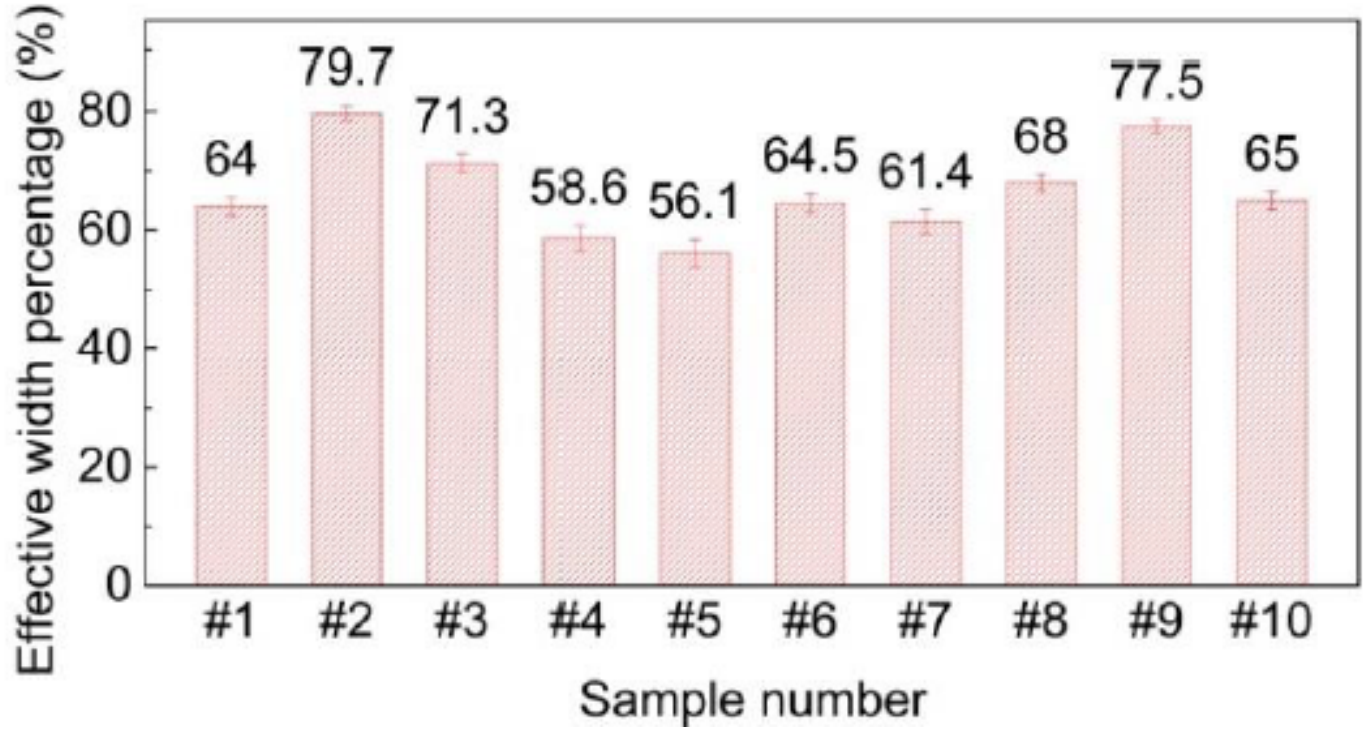

Figure 5

Effective width percentage of \#1 - \#10 thin-walls

Figure 6

Effective width percentage as a function of (a) arc current, (b) scanning speed and (c) ratio of EP to EN

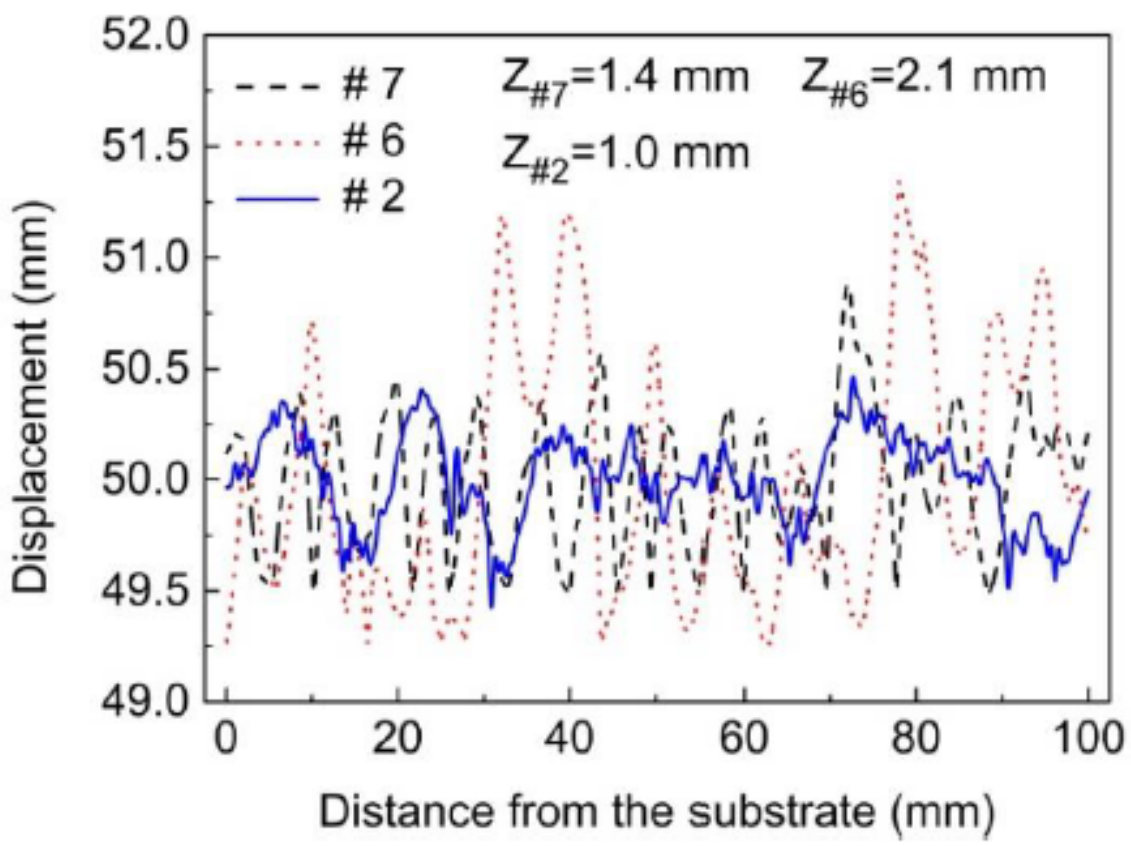


Figure 7

Side profile under different process parameters, where $Z$ is machining allowance

\section{Figure 8}

Thin-wall appearance with the optimal process parameter

\section{Figure 9}

Error rates between the actual value and predicted value of deposition width and height 

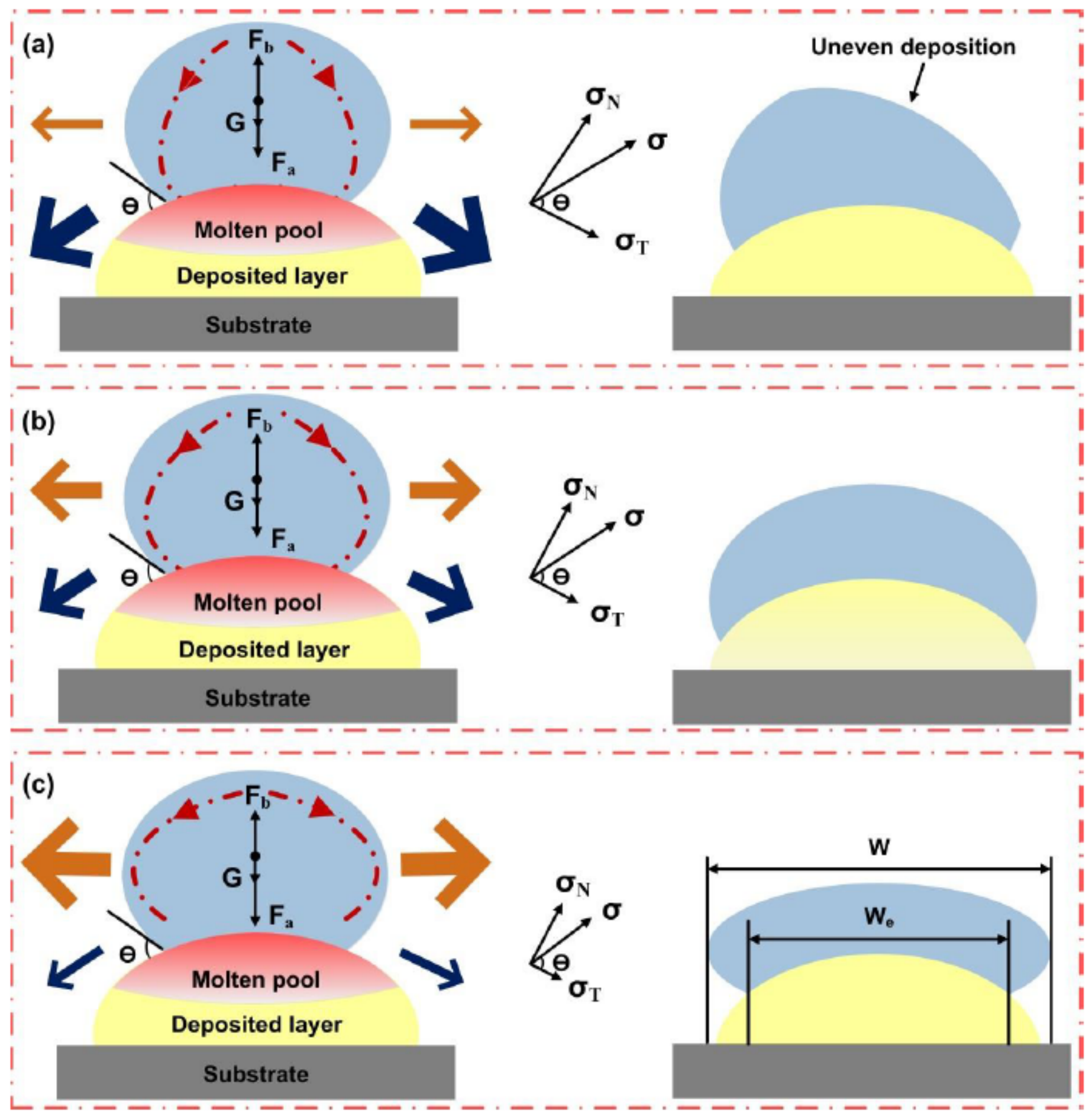

Figure 10

Schematic diagram of droplets force analysis and spread: (a) \#1, \#7, \#8, (b) \#2, \#9 and (c) \#3, \#4, \#5, \#6, $\# 10$ 


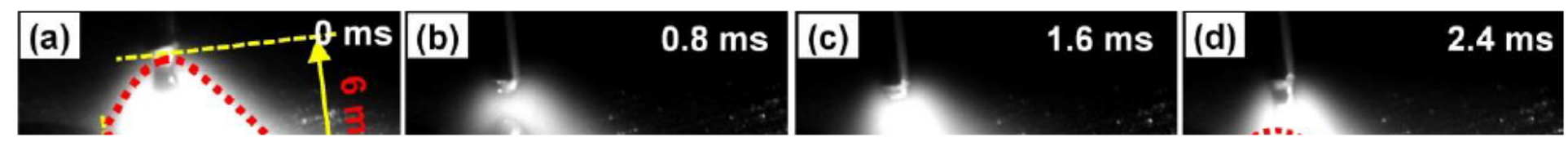

Figure 11

High-speed photographs of droplet transfer and molten pool: (a-d) EP-Pulse phase, (e-h) EN- CMT phase 